\section{Photoperiod, Irradiance, and Temperature Influence Flowering of Hamelia patens (Texas Firebush)}

\author{
Allan M. Armitage \\ Department of Horticulture, University of Georgia, Athens, GA 30602-7273
}

Additional index words. light, visible bud, long days

Abstract. Hamelia patens Jacq. (Texas firebush) is a long-day plant for flower initiation and flower development; however, flower development is more sensitive to photoperiod than is flower initiation. The critical photoperiod for flower development at $25 \mathrm{C}$ is between 12 and 16 hours. Flowering was delayed under low light conditions, and plant dry weight was heavier and flowering time was earlier for plants grown at a constant 25 or $30 \mathrm{C}$ than at $20 \mathrm{C}$. A greenhouse environment with a 16-hour photoperiod and moderately high temperature (25C) would be appropriate for production of $\boldsymbol{H}$. patens.

Hamelia patens is a woody shrub belonging to the Rubiaceae family and native to South America. Plants grow 1.5 to $3 \mathrm{~m}$ tall and bear whorled leaves and bright scarlet flowers arranged in a 3-5 rayed terminal cyme (Bailey, 1951). Plants are being used as landscape plants in the southern United States and in the tropics. They are most floriferous in the summer months under long days (LD) and warm weather, and the spectacular flowering display makes this a potential potted plant for year-round or summer sales to supplement other crops.

The ability to flower the plant on demand is a prerequisite to successful introduction of any new crop, regardless of sales time. As expected with a species of tropical origin, observation showed that flowering is enhanced significantly by moderately high temperatures (>22C), while lower temperatures delay flowering and growth. No information was found on environmental control of flowering of Hamelia; however, some data on other ornamental species of Rubiaceae have been published. Pentas lanceolata Benth. (galaxy flower) flowered 7 to 10 days earlier under LD than short days (SD). Six weeks of highintensity discharge light during daylight hours also significantly accelerated flowering (Armitage, 1988). When root temperature of Ixora coccinea L. was increased from 34 to 40C, shoot : root weight ratio increased and shoot sugar: starch ratio decreased. In general, 34C appeared to be the optimum root temperature (Ingram et al., 1986). Bouvardia $\times$ domestica Salisb., a greenhouse cut-flower crop, is a SD plant with a critical photoperiod for flower initiation between 10 and $12 \mathrm{~h}$ (Vonk Noordegraaf, 1983, 1985). Vegetative growth is promoted by LD lighting with incan-

Received for publication 28 Feb. 1994. Accepted for publication 18 Oct. 1994. Appreciation is expressed to Meg Green for technical assistance. Many thanks to American Floral Endowment and Gloeckner Foundation for support of this work. The cost of publishing this paper was defrayed in part by the payment of page charges. Under postal regulations, this paper therefore must be hereby marked advertisement solely to indicate this fact. descent lamps or by cyclic lighting (Vonk Noordegraaf, 1985).

The objectives of these studies were to determine the influence of photoperiod, irradiance, and temperature on the production of Hamelia patens as a potted plant.

\section{Materials and Methods}

Photoperiod. Photoperiod experiments were conducted during 1992 and 1993. Cuttings of stock plants were taken in early June in both years and rooted under intermittent mist and a 25 peat : 75 perlite mixture. Fortyfive rooted cuttings were selected for uniformity and potted in $385-\mathrm{ml}(10-\mathrm{cm})$ pots in a commercial greenhouse medium (Fafard \#2; Conrad Fafard, Agawam, Mass.). Plants were grown in the greenhouse where average cycles were $26 \mathrm{C}$ day/22C night. About 6 weeks after the cuttings were taken, the terminals of all plants were pinched to four nodes to remove latent flower buds. Fifteen plants were placed randomly in growth chambers of 8-, 12-, or 16$h$ photoperiods. Plants were arranged in the chambers so that cumulative photosynthetic photon flux (PPF) was equal over $24 \mathrm{~h}$. The PPF was $300 \pm 20,200 \pm 15$, and $150 \pm 10$ $\mu \mathrm{mol} \cdot \mathrm{m}^{-2} \cdot \mathrm{s}^{-1}$ for $8-, 12-$, and $16-\mathrm{h}$ photoperiods, respectively. All chambers were set at constant $25 \pm 3 \mathrm{C}$ for the duration of the experiments. Plants were fertilized with $200 \mathrm{mg} \mathrm{N} /$ liter constant liquid feed, using $20 \mathrm{~N}-12.6 \mathrm{P}-$ $16.6 \mathrm{~K}$ of a commercial fertilizer. Plants were irrigated with clear water every fourth watering to reduce buildup of soluble salts. The experiments were conducted similarly in both 100 days.

Tukey's $w$ mean separation, $P=0.05$.

ss Nonsignificant. years; however, chambers were randomized each year and data for the two years were pooled. The time to visible flower bud (flower buds $>0.5 \mathrm{~cm}$ ) and anthesis were determined, and plant height, dry weight, and leaf surface area were measured after anthesis was complete. The experiment ended 100 days after placement in the chambers. Data were tested by analysis of variance (ANOVA).

Irradiance. For the irradiance experiments, cuttings of stock plants were taken in Jan. 1991 and rooted as discussed above. Thirtysix rooted cuttings were selected for uniformity and potted (385-ml pots) in the same brand of medium as for the photoperiod experiments. Plants were grown for 6 weeks in the greenhouse where average cycles were $22 \mathrm{C}$ day/17C night. On 28 Jan., the terminals of all plants were pinched to four nodes. Twelve plants were placed in growth chambers at 107 $\pm 7,210 \pm 10$, or $325 \pm 25 \mu \mathrm{mol} \cdot \mathrm{m}^{-2} \cdot \mathrm{s}^{-1}$. The photoperiod in each chamber was $18 \mathrm{~h}$ and was set at $25 \pm 3 \mathrm{C}$ day and night. Plants were irrigated and fertilized as discussed above. The time to visible bud was determined, and plant height, leaf surface area, and dry weight of the aboveground portion were measured when flower buds were first visible. The experiment ended 100 days after placement in the chambers.

Temperature. For the temperature experiments, cuttings of stock plants were taken on 24 Aug. 1990 and rooted as discussed above. Forty-five rooted cuttings were selected for uniformity and potted in $385-\mathrm{ml}$ pots in the medium noted above. Plants were grown in the greenhouse for 6 weeks where average cycles were $24 \mathrm{C}$ day/21C night. On 15 Oct., the terminals of all plants were pinched to four nodes. Fifteen plants were placed in growth chambers at a constant 20,25 , or $30 \pm 2 \mathrm{C}$ and a 16-h photoperiod. Plants were irrigated and fertilized as discussed above. The time to visible bud was determined, and plant height, leaf surface area, and dry weight were measured when flower buds were first visible. The experiment ended 100 days after placement in the chambers.

In all experiments, data were tested by ANOVA, and Tukey's $w$ mean separation (HSD), $P=0.05$, was used when applicable.

\section{Results and Discussion}

Photoperiod. Although flower buds were formed under all photoperiods, not all plants within a treatment reached visible bud by 100 days (Table 1). At the 16-h photoperiod, $100 \%$ of the plants initiated flowers, but only about

Table 1. The influence of photoperiod on flowering and growth of Hamelia patens. Experiment ended after

\begin{tabular}{|c|c|c|c|c|c|c|c|}
\hline \multirow{2}{*}{$\begin{array}{l}\text { Photoperiod } \\
\text { (h) }\end{array}$} & \multicolumn{2}{|c|}{ Visible bud } & \multicolumn{2}{|c|}{ Anthesis } & \multirow{2}{*}{$\begin{array}{c}\text { Plant } \\
\text { ht }(\mathrm{cm})\end{array}$} & \multirow{2}{*}{$\begin{array}{c}\text { Leaf } \\
\text { surface area } \\
\left(\mathrm{cm}^{2}\right)\end{array}$} & \multirow[b]{2}{*}{ Dry wt (g) } \\
\hline & $\%$ & Days to & $\%$ & Days to & & & \\
\hline 8 & 60 & 74 & 0 & --- & 25.3 & 1234 & 8.2 \\
\hline 12 & 73 & 70 & 20 & 93 & 23.5 & 1101 & 6.6 \\
\hline 16 & 100 & 67 & 100 & 87 & 20.0 & 1131 & 5.8 \\
\hline $\mathrm{HSD}^{\mathrm{z}}$ & 8 & NS & 4.2 & NS & 1.4 & & \\
\hline
\end{tabular}




\section{Crop Production}

two-thirds of the plants responded under 12and 8-h photoperiods (Table 1). While initiation occurred in at least $60 \%$ of the plants with 8 and $12 \mathrm{~h}$, flower development was totally arrested in the 8-h photoperiod and only $20 \%$ of the plants under $12 \mathrm{~h}$ reached anthesis. In both of these short photoperiods, flower development was erratic and few flowers completely opened. Leaf surface area was similar under all treatments, but plants were taller with the 8- than the 16-h photoperiod. Dry weight was highest under $8 \mathrm{~h}$. These differences may be attributed to the longer growth time the plants remained in the chambers when grown under SD.

Irradiance. The main difference between irradiance treatments was the significant delay of flowering under low light compared to plants subjected to high and medium irradiances (Table 2). The flowering response was similar for plants under high and medium irradiances. Plants under low irradiance were significantly taller than plants under high light, but no other height differences occurred. Plants grown under low irradiance had a lower dry weight and a smaller leaf surface area than plants in other treatments. These data combined with the delay in flowering suggest that Hamelia does not tolerate low-light conditions.

Temperature. Growth at 25 or $30 \mathrm{C}$ accelerated flowering of Hamelia compared to production at 20C (Table 3 ). Leaf surface area and dry weight were reduced at 20C compared with growth at the other temperatures tested (Table 3). Such a response is not surprising considering that Hamelia patens is native to warm regions of Mexico, Paraguay, and the West Indies.

Our data suggest that Hamelia patens is a quantitative LD plant with a critical photoperiod between 12 and $16 \mathrm{~h}$. The effect of LD

Table 2. The influence of irradiance on flowering and growth of Hamelia patens. Plants were grown at 16$\mathrm{h}$ photoperiods and $25 \mathrm{C}$.

\begin{tabular}{lcccc}
\hline $\begin{array}{l}\text { Irradiance level } \\
\left(\mu \mathrm{mol} \cdot \mathrm{m}^{-2} \cdot \mathrm{s}^{-1}\right)\end{array}$ & Days to visible bud & $\begin{array}{c}\text { Plant ht } \\
(\mathrm{cm})\end{array}$ & Dry wt $(\mathrm{g})$ & $\begin{array}{c}\text { Leaf surface area } \\
\left(\mathrm{cm}^{2}\right)\end{array}$ \\
\hline Low $(107)$ & 100 & 30.5 & 10.1 & 944 \\
Medium $(210)$ & 74 & 29.1 & 15.1 & 1187 \\
High $(325)$ & 69 & 24.0 & 15.5 & 1060 \\
HSD $^{2}$ & 7 & 6.1 & 4.7 & 104.8 \\
\hline
\end{tabular}

'Tukey's $w$ mean separation, $P=0.05$.

Table 3. The influence of temperature on flowering and growth of Hamelia patens. Photoperiod was $16 \mathrm{~h}$.

\begin{tabular}{lccc}
\hline \hline Temp $\left({ }^{\circ} \mathrm{C}\right)$ & Days to visible bud & $\begin{array}{c}\text { Leaf surface area } \\
\left(\mathrm{cm}^{2}\right)\end{array}$ & Dry wt $(\mathrm{g})$ \\
\hline 20 & 95 & 1104 & 4.5 \\
25 & 72 & 1505 & 6.3 \\
30 & 65 & 1448 & 6.5 \\
HSD $^{2}$ & 7 & 65.3 & 0.7 \\
\hline
\end{tabular}

Tukey's $w$ mean separation, $P=0.05$.

appears to be more critical to flower development (time from visible bud to anthesis) than to flower initiation (to visible bud). This result resembles those with chrysanthemum [Dendranthema $\times$ grandiflorum (Ramat) Kitamura] (Schwabe, 1951) and velvet sage (Salvia leucantha Cav.) (Armitage and Laushman, 1989). Plants may be forced to flower for pot plant or bedding use under continuous LD, high light, and warm conditions. During winter months in the northern hemisphere, flowering plants may be produced with manipulation of photoperiod. Supplemental lighting during the LD phase would also be useful but not a necessity. The economics of maintaining a warm environment might be questionable for growers in temperate climates; however, southern areas of the United States and producers in tropical areas would have little problem. Also, as the data support, Hamelia would be particularly useful as a landscape or potted plant for summer production.

\section{Literature Cited}

Armitage, A.M. 1988. Influence of photoperiod, supplemental light and growth regulators on growth and flowering of Pentas lanceolata. HortScience 23:349-351.

Armitage, A.M. and J.M. Laushman. 1989. Photoperiodic control of flowering of Salvialeucantha. J. Amer. Soc. Hort. Sci. 114:755-758.

Bailey, L.H. 1951. Manual of cultivated plants. Macmillan, New York.

Ingram, D.L., C. Ramcharan, and T.A. Nell. 1986. Response of container-grown banana, ixora, citrus, and dracena to elevated root temperatures. HortScience 21:254-255.

Schwabe, W.W. 1951. Factors controlling flowering in the chrysanthemum: II. Daylength effects on the further development of inflorescence buds and their experimental reversal and modification. J. Expt. Bot. 2:223-237.

Vonk Noordegraaf, C. 1983. The influence of light and temperature on growth and development of Bouvardia. Acta Hort. 147:187-191.

Vonk Noordegraaf, C. 1985. Bouvardia, p. 49-52. In: A.H. Halevy (ed.). Handbook of flowering. vol. 5. CRC Press, Boca Raton, Fla. 